\title{
Morphogenetics of early thyroid development
}

\author{
Henrik Fagman ${ }^{1}$ and Mikael Nilsson ${ }^{2}$ \\ ${ }^{1}$ Department of Pathology and ${ }^{2}$ Department of Medical Biochemistry and Cell Biology, Institute of Biomedicine, The Sahlgrenska Academy at the University of \\ Gothenburg, Gula Stråket 8, 41345 Göteborg, Sweden \\ (Correspondence should be addressed to H Fagman; Email: henrik.fagman@gu.se)
}

\begin{abstract}
The thyroid develops from the foregut endoderm. Yet uncharacterized inductive signals specify endoderm progenitors to a thyroid cell fate that assembles in the pharyngeal floor from which the primordium buds and migrates to the final position of the gland. The morphogenetic process is regulated by both cell-autonomous (e.g. activated by NKX2-1, FOXE1, PAX8, and HHEX) and mesoderm-derived (e.g. mediated by TBX1 and fibroblast growth factors) mechanisms acting in concert to promote growth and survival of progenitor cells. The developmental role of TSH is limited to thyroid differentiation set to work after the gross anatomy of the gland is already sculptured. This review summarizes recent advances on the molecular genetics of thyroid morphogenesis put into context of endoderm developmental traits and highlights established and novel mechanisms of thyroid dysgenesis of potential relevance to congenital hypothyroidism in man.
\end{abstract}

Journal of Molecular Endocrinology (2011) 46, R33-R42

\section{Introduction}

Congenital hypothyroidism $(\mathrm{CH})$ affects 1:2700 newborns according to a recent European survey (Loeber 2007). With a lower cutoff level for TSH screening (10-12 mU/l) the incidence increases to $1: 1500$ with most cases presenting with a normally located thyroid gland. With the higher TSH screening cutoff $(20 \mathrm{mU} / \mathrm{l})$ that has traditionally been used, impaired structural development of the thyroid gland (thyroid dysgenesis, TD) is instead the leading cause of $\mathrm{CH}$ (Corbetta et al. 2009). TD is morphologically highly variable, ranging from hypoplasia or total absence of the gland (variably referred to as athyreosis, thyroid agenesis, or aplasia) to ectopia of thyroid tissue (lingual or at more distant locations; Kratzsch \& Pulzer 2008). The variable features of TD indicate that the pathogenesis involves multiple developmental defects affecting such different processes as specification and expansion of progenitor cells, budding and migration of primordial tissues, and proliferation of cells forming the embryonic thyroid. Congenital heart defects are overrepresented among these children, suggesting a developmental relationship between the thyroid and the cardiovascular system (Olivieri et al. 2002).

In higher vertebrates the thyroid develops from the anterior foregut endoderm (Fig. 1) in which progenitor cells expressing four critical transcription factors,
NKX2-1, PAX8 (or Pax2.1a in zebrafish), FOXE1, and HHEX, assemble to form the thyroid bud (Fagman \& Nilsson 2010). The growing bud subsequently delaminates from the pharyngeal endoderm and moves downward to the final anatomical position of the thyroid, a process that also involves incorporation of the ultimobranchial bodies whereby C-cell precursors are brought to the thyroid. During morphogenesis, embryonic tissues surrounding the developing thyroid rapidly become increasingly complex designated by the formation of a series of pharyngeal arches and pouches collectively constituting the pharyngeal metamere, a repetitive motif of body segmentation (Graham 2008). The endoderm itself and the adjacent mesoderm provide morphogenetic signals that act reciprocally and contribute to segmentation of the pharyngeal region (Zhang et al. 2005, 2006, Arnold et al. 2006, Graham 2008). The picture is further complicated by the fact that the foregut endoderm is responsive to diffusible factors derived from the developing heart (Kaestner 2005, Zaret \& Grompe 2008). The key questions in thyroid development, which remain to be elucidated, are how a subset of undifferentiated endodermal cells is directed toward a thyroid fate, and which embryonic factors drive the proliferation and differentiation of thyroid progenitors. Notably, TSH acts on the thyroid first in late development, i.e. after the morphogenetic process is completed (Postiglione et al. 2002). 
A wealth of information on the development of other endoderm derivatives such as the lungs, liver, and pancreas is rapidly accumulating and a coherent picture on the molecular machinery involved is starting to emerge (Zaret \& Grompe 2008). In comparison, current knowledge on inductive and regulatory signals of thyroid morphogenesis is still limited. This review will therefore start with a more general outlook on current concepts of endoderm development and regionalization in early foregut development that might be relevant for the understanding of thyroid specification. Recent advances on early stages of embryonic thyroid development will thereafter be discussed. Finally, current views on the causes of TD in human patients and some aspects of embryonic stem (ES) cells will be briefly considered. For recent comprehensive reviews on thyroid morphogenesis in the most important animal models (mice, chicken, and zebrafish), see Porazzi et al. (2009) and Fagman \& Nilsson (2010).

\section{How are organs specified in the early endoderm?}

General aspects of endoderm development and regionalization are discussed in detail in excellent recent reviews (Grapin-Botton \& Constam 2007, Zorn \& Wells 2009). In this review, we will consider only a few aspects of particular relevance in the context of thyroid development, which highlight potentially novel mechanisms for specification defects that might underlie thyroid agenesis/athyreosis. The key regulators of endoderm formation at gastrulation are NODAL factors (of the transforming growth factor $\beta$ family) and an elaborate network of downstream components including the transcription factors FOXA2, SOX17, and GATA4-6 (Grapin-Botton \& Constam 2007, Zorn \& Wells 2009). As the definitive endoderm is rapidly remodeled into the primitive gut tube, the endoderm becomes broadly regionalized along the anteriorposterior axis designated by discrete patterns of gene expression. For instance, foregut identity is closely linked to the expression of HHEX, FOXA2, and SOX2. Patterning is further refined and elaborated by overlapping growth factor signals from nearby tissue layers to precisely delimit the regions of primordial outgrowth that initiates the process of organogenesis (Zorn \& Wells 2009). Regional movements in the early endoderm appear to be highly dynamic as demonstrated by cell tracking studies on the developing liver and pancreas, which show that initially far distant progenitors converge into their prospective anlagen (Tremblay \& Zaret 2005, Franklin et al. 2008). In zebrafish, detailed fate mapping has revealed that thyroid precursors derive from the endoderm at the level of the mid-hindbrain boundary closely apposed to the anterior lateral plate mesoderm from which the heart later develops (Wendl et al. 2007). BrdU labeling studies in mouse embryos suggest that the thyroid bud grows by recruitment of cells from the neighboring endoderm rather than on-site proliferation of progenitors within the thyroid placode (Fagman et al. 2006). Cell tracking studies might be helpful to elucidate more precisely the region of the anterior endoderm from which the thyroid cell lineage derives in higher vertebrates.

Endoderm progenitor fate is influenced by the surrounding tissues such as the notochord and yet undifferentiated mesoderm (Wells \& Melton 2000). Of particular interest, the early foregut rapidly changes its relationship to the mesoderm as the gut tube closes and glandular derivatives of the endoderm and the heart and central vessels develop in a coordinated manner. In this process, mesoderm regions that generate inductive signals such as fibroblast growth factors (FGFs), WNT, retinoic acid (RA), and bone morphogenetic proteins seem to gradually shift their projection toward the adjacent endoderm. This means that the response to a given morphogen is spatially and temporally restricted, and that this influence changes topologically over time to regulate endoderm development and differentiation. For example, in Xenopus, wnt signals are initially necessary to generate anterior endoderm, thereafter repressed to maintain foregut identity, and in a subsequent phase re-expressed to participate in hepatic organogenesis (McLin et al. 2007, Zorn \& Wells 2009). The actual concentration of a given morphogen also affects cell fate as demonstrated in explant cultures of the endoderm: low levels of FGF promote the expression of pancreatic genes, intermediate doses activate a liver program, and high concentrations of the same factor induce NKX2-1 specific for thyroid and lung progenitor cells (Serls et al. 2005).

The homeobox transcription factor HHEX has a central role in early thyroid development (Martinez Barbera et al. 2000), although the mechanism is yet largely unknown. Transcription factors have generally been assumed to exert their influence on the specification of endoderm derivatives by cell-autonomous regulation of tissue-specific genes. However, a more indirect mode of action of HHEX on organ specification in the embryonic endoderm has been demonstrated more recently. During gut tube closure, HHEX promotes endoderm growth beyond the cardiogenic mesoderm. This appears crucial to divert the pancreatic lineage from a common hepatopancreatic anlage and the juxtapositioned heart mesoderm that positively regulates hepatic differentiation (Bort et al. 2004). This is a conceptually interesting mechanism by which a transcription factor influences organ specification in the endoderm by modifying the position of receptive domains to inductive signals generated in the nearby mesoderm. The complexity of morphogenetic 
regulation is further emphasized by the fact that HHEX-mediated effects may also involve inhibitory signals. For example, the negative control of hhex expression in the endoderm by the wnt/ $\beta$-catenin signaling pathway must be locally repressed to establish and maintain foregut identity in Xenopus (McLin et al. 2007). wnt antagonism further induces heart formation via activation of hhex in the endoderm (Foley \& Mercola 2005). Foregut endoderm and adjacent mesoderm development are thus regulated reciprocally by multiple non-cell-autonomous mechanisms.

Taken together, as the primordia of endodermderived organs (thyroid, lung, liver, and pancreas) emerge from the foregut (Fig. 1) this is not due to a one-to-one mode of action of organ-specific inductive signals, but the consequence of differential responsiveness of endoderm progenitors to a combination of broadly distributed morphogens. These factors are generated in the mesoderm and exist as graded concentrations in the local environment during restricted time windows as embryonic development continues (Grapin-Botton \& Constam 2007, Bayha et al. 2009, Zorn \& Wells 2009). With this perspective in mind, it can be hypothesized that thyroid agenesis may be caused by mismatched juxtapositioning of the prospective thyroid field in the foregut endoderm to inductive signals in the nearby mesoderm, or primarily lack of or inappropriate levels of these signals, rather than by impaired expression or

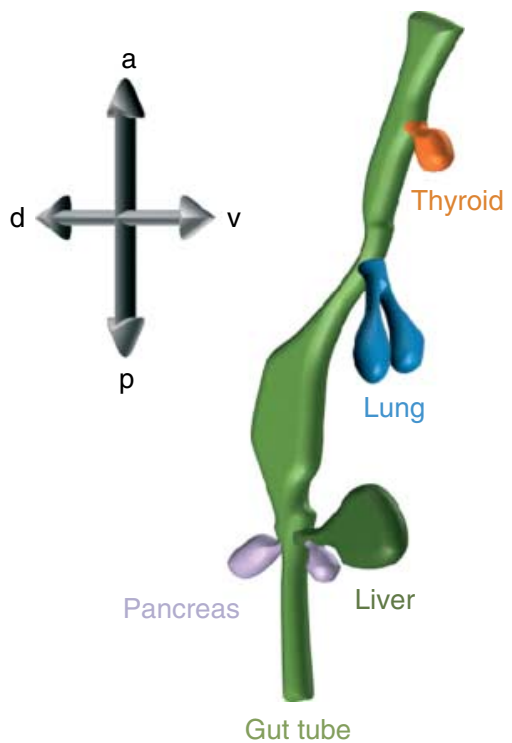

Figure 1 Organ bud outgrows along the anterior-posterior axis of the embryonic gut tube. The thyroid delaminates from the most anterior portion of the ventral foregut endoderm; close to the thyroid bud are the thymus and parathyroid primordia and the ultimobranchial bodies formed from lateral endoderm of the posterior pharyngeal pouches (not shown). Note that the developing pancreas is specified as separate ventral and dorsal primordia. $a$, anterior; $p$, posterior; $v$, ventral; $d$, dorsal.

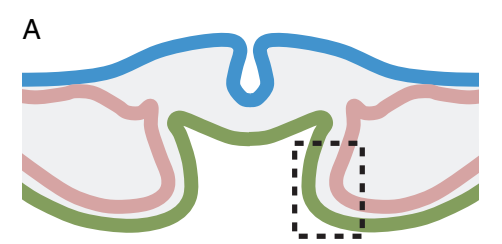

B
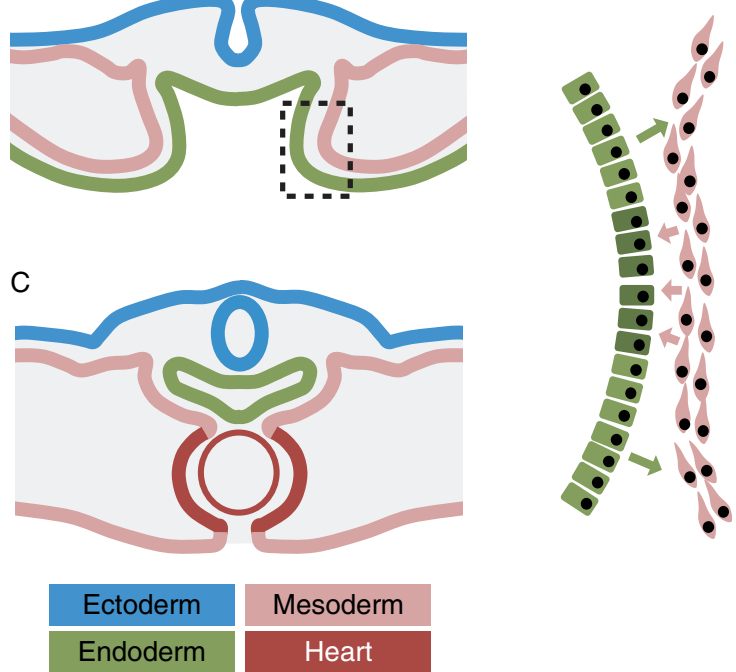

Figure 2 (A) A schematic illustration of germ layer interactions during formation of the primitive gut tube. The endoderm is in close proximity to the lateral plate/cardiogenic mesoderm, providing an anatomical foundation for cross signaling between cell populations (boxed region; see B). The spatial relationship in early development between the endoderm destined to a thyroid fate and lateral plate mesoderm/cardiac mesoderm has not yet been clearly defined in mice. (B) Mesodermal cells may elaborate diffusible factors that affect the morphogenesis in the adjacent ventrolateral endoderm. Moreover, signaling in the opposite direction (i.e. from endoderm to mesoderm) occurs. It is assumed that the endoderm in this location may contain the prospective thyroid field in which thyroid progenitor cells are specified before entering the thyroid placode in the pharyngeal floor not yet formed. (C) After the gut tube is closed, the thyroid placode is located in the midline of the pharyngeal endoderm directly apposed to the developing heart and outflow tract (see Fig. 3) Adapted, with kind permission from Sinauer Associates Inc., from Gilbert SF 2000 Lateral plate mesoderm and endoderm. In Developmental Biology, 6th edn, pp 471-501. Sunderland: Sinauer Associates, Inc.

function of a single putative thyroid-specific master gene. The close spatial relationship between the ventral pharyngeal endoderm and the cardiogenic mesoderm, and the fact that these tissues are mutually dependent on reciprocal signaling for progenitor cell proliferation and survival (Cai et al. 2003), raise the possibility that concurrent thyroid and heart malformations may develop from shared pathogenetic mechanisms operating in early organogenesis. The concepts of this hypothesis are summarized in Fig. 2.

\section{What can we learn about the embryonic thyroid from animal models?}

Early thyroid development in mice depends on the conjoined activity of NKX2-1, PAX8, FOXE1, and HHEX to proceed normally (De Felice \& Di Lauro 2007, Fagman \& Nilsson 2010). However, neither of these 
transcription factors is alone required for the specification of thyroid progenitors in the foregut endoderm (Parlato et al. 2004). Hence, in mutant mouse embryos deficient in NKX2-1, PAX8, FOXE1, or HHEX the thyroid primordium is specified and starts to form a bud that later regresses by yet unknown mechanisms, although lack of survival signal(s) leading to progenitor cell death by apoptosis is likely involved. The only exception to this fate is Foxe1 mutants in which nearly $50 \%$ of the embryos show a sublingual thyroid rudiment mimicking the picture of thyroid ectopia (De Felice et al. 1998). Further studies have proposed that FOXE1 regulates migration of the delaminated thyroid primordium by a cell-autonomous mechanism, i.e. the drive of migration is intrinsic to the thyroid precursors (Parlato et al. 2004). The mechanism and target gene(s) activated by FOXE1 to accomplish this effect have not been identified. In zebrafish, the Foxe1 ortholog is expressed in the thyroid progenitors but knockdown experiments did not reveal any effect on thyroid morphogenesis (Nakada et al. 2009). It should be kept in mind that the zebrafish thyroid forms follicles very early during development (Wendl et al. 2002), and that such long-distance migration of a solid nest of undifferentiated progenitors as seen in the mouse embryo might not take place. It is thus possible that some steps in thyroid morphogenesis are fundamentally different in mice and fish and therefore regulated differently.

Besides NKX2-1, NKX2-3 and NKX2-5 are expressed in the thyroid bud at the early stages of development (Lien et al. 1999, Biben et al. 2002). NKX2-5 is particularly interesting since it is expressed also in the developing heart (Lints et al. 1993), suggesting that this transcription factor regulates common developmental traits in the two organ primordia. Indeed, NKX2-5-deficient mouse embryos show thyroid bud hypoplasia in addition to cardiac defects (Lyons et al. 1995, Biben et al. 2000, Dentice et al. 2006). In addition, a number of NKX2-5 mutations were detected in patients with thyroid ectopia or athyreosis (Dentice et al. 2006). Interestingly, NKX2-5 mutations have been identified in human patients with a range of other cardiac abnormalities (Schott et al. 1998). NKX2-5 may thus be one of several factors associated with the increased prevalence of cardiac malformation in children with CH (Olivieri et al. 2002). As NKX2-5 binds to and activates the same promoter regions as NKX2-1 (Ray et al. 1996) it is possible that the phenotype is partially compensated for by functional redundancy between these transcription factors.

Animal embryo studies also show that factors acting non-cell autonomously, i.e. the factor is not expressed or produced by the target cells themselves, influence the earliest stages of thyroid morphogenesis. For example, in both zebrafish (Stafford \& Prince 2002) and chick (Bayha et al. 2009) it is known that RA generated in the mesoderm confers a posterior identity to the endoderm and that experimentally induced higher RA levels shift posterior endoderm markers anteriorly. A consequence of increased RA activity is the absence of thyroid progenitors as signified by the lack of Hhex and Nk2.1a expression in the prospective thyroid field. Conversely, repressed RA activity alters the positional identity of thyroid progenitors toward the posterior foregut in zebrafish (Stafford \& Prince 2002). This indicates that RA negatively regulates the adoption of a thyroid fate in responsive regions of the endoderm. However, additional factors are most likely required, as suggested from the observations in chick embryos that deficiency of RA leading to the enlargement of the HHEX-positive domain in the foregut endoderm is not sufficient to increase the number of NKX2-1-expressing cells (Bayha et al. 2009). It is worth mentioning that RA and FGF4 are known to coordinately regulate endoderm patterning and that FGF4 also represses the establishment of anterior cell identity in the chicken gut tube (Dessimoz et al. 2006). A putative role of FGF4 in early thyroid development is yet to be investigated.

Other FGFs derived from the mesoderm evidently influence thyroid morphogenesis. Mouse thyroid and lung development take place rather closely in the anterior foregut and both primordia require the cellautonomous action of NKX2-1 to proceed normally (Fig. 3). Common developmental traits are further suggested by the fact that both organs are missing in FGF10-deficient mouse embryos (Ohuchi et al. 2000). The mechanism has not been elucidated in detail, but indirect evidence suggests that FGF10 is differently regulated in thyroid and lung regions respectively. First, the expression of FGF10 in lung mesenchyme depends on RA whereas FGF10 in mesoderm adjacent to the thyroid bud does not (Desai et al. 2004). Consequently, in mice deficient of RA activity the lung bud fails to develop whereas thyroid morphogenesis is seemingly unperturbed (Desai et al. 2004). Second, although the FGF10 expression in the vicinity of both lung and thyroid is controlled by canonical WNT signaling (Chen et al. 2010), lung specification is abolished while thyroid progenitors are readily specified in $W n t 2 / 2 b$ knockout mouse embryos (Goss et al. 2009).

Studies in both zebrafish and mice indicate that Fgf8 has a central role in early thyroid development. Fgf8deficient zebrafish embryos show a severely hypoplastic thyroid (Wendl et al. 2007). The tissue source of Fgf8 regulating this process is not yet identified, although it requires the transcription factor dHand that is expressed in cardiac mesoderm. Hence, locally administered Fgf8 (or Fgfl, Fgf2) rescues the thyroid phenotype in dHand-deficient embryos. As Fgf8 is unable to ectopically induce thyroid progeny in other parts of the endoderm (Wendl et al. 2007), this suggests that the action is permissive rather than inductive on 


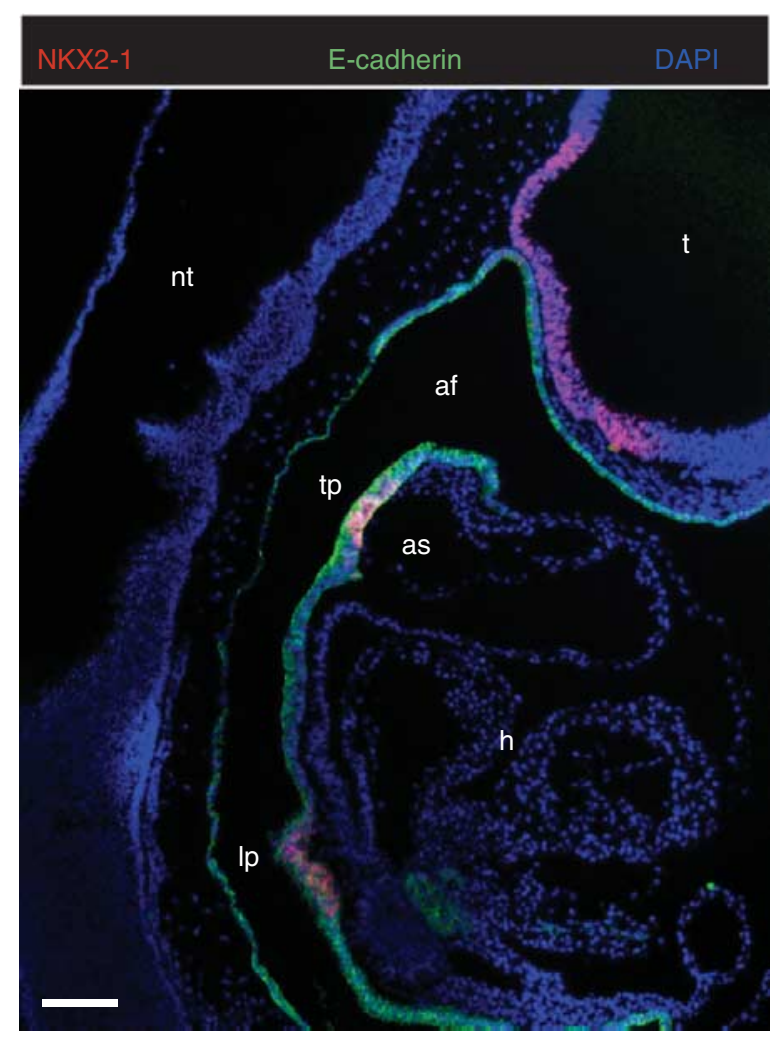

Figure 3 Regionalization and organ specification in the anterior foregut of an E9.5 mouse embryo. In the otherwise inconspicuous endoderm lining of the gut tube (stained for E-cadherin expression) discrete subsets of cells destined to thyroid and lung lineages are recognized by their expression of NKX2-1. Outside the endoderm, NKX2-1 is also abundant in neuroectoderm in the telencephalic floor. Knockout of $N k x 2-1$ in mice leads to athyreosis, severe lung dysplasia, and forebrain anomalies (Kimura et al. 1996). A corresponding phenotype is observed in patients haploinsufficient for NKX2-1 (Krude et al. 2002). Note that the thyroid anlage is seen closely apposed to the cardiac outflow tract forming the aortic sac. af, anterior foregut; as, aortic sac; $\mathrm{h}$, heart; Ip, lung primordium; nt, neural tube; t, telecephalon; tp, thyroid primordium. Scale bar $=100 \mu \mathrm{m}$.

thyroid specification in zebrafish. In mice, FGF8 was recently shown to stimulate the generation of endoderm progenitors committed to a thyroid fate (Lania et al. 2009). This may in part explain thyroid hypoplasia in mice deficient of TBX1, previously known to regulate embryonic thyroid growth (Fagman et al. 2007). TBX1 is expressed in the mesoderm adjacent to the thyroid primordium (Fagman et al. 2007). Ablation of Tbx1 specifically in the mesoderm mimics the thyroid phenotype of $T b x 1$ null mice and overexpression of $\mathrm{Fg} f 8$ in the mesoderm partly rescues the thyroid defect (Lania et al. 2009). Together, this provides a direct proof of a central role of mesoderm in thyroid development in higher vertebrates. Moreover, in view of the fact that $T B X 1$ is the major candidate gene in DiGeorge or $22 q 11$ syndrome this suggests that hypothyroidism sporadically encountered in these patients (Stagi et al. 2010) may be the result of TD on the basis of an impaired non-cell-autonomous mechanism.

It was recently reported that the final size of the mouse pancreas critically depends on the number of progenitor cells initially generated in the endoderm (Stanger et al. 2007); at difference with the concurrently developed liver, the pancreas has no capacity of compensatory growth in late development. The data discussed earlier for Tbx 1 mutant mice (Lania et al. 2009) and similar findings in cyclops (a Nodal ligand), $d H a n d$, and $f g f 8$ zebrafish mutants (Elsalini et al. 2003, Wendl et al. 2007) raise the possibility that the number of progenitors recruited to a thyroid fate may limit the final size of the thyroid gland by a similar mechanism. However, there are observations suggesting that embryonic thyroid growth not only depends on factors involved in preformation of the anlage in the endoderm but that later events in organogenesis also contribute. For example, the thyroid develops closely associated with embryonic vessels (Fagman et al. 2006). In Tbx1 null mutants, the hypoplastic thyroid reminiscent of hemiagenesis in the mature phenotype probably relates to failure of the primordium to establish contact with the aortic sac and branchial arch vessels during critical stages of budding and migration, and that this seemingly interfere with the bilobation process and further expansion of the thyroid lobes (Fagman et al. 2007). The importance of FGFs for the separation, migration, and survival of pharyngeal endoderm-derived organs is further suggested from studies on mice deficient in FRS2 $\alpha$, a docking protein that links FGF receptor activation to downstream signaling pathways (Kameda et al. 2009). It is thus conceivable that fetal thyroid size is determined both by the progenitor cell number generated while the primordium is still an integral part of the foregut endoderm and by the influence of surrounding embryonic tissues that promote progenitor cell proliferation in the subsequent morphogenetic stages of thyroid development (Fig. 4). An interesting question is whether a congenitally hypoplastic thyroid shares the ability of the normal gland to respond to goitrogenic stimuli, e.g. iodine deficiency, or whether reactive compensatory growth after birth is restrained by properties inherited to the developmental defect. If so, this would increase the risk of developing overt hypothyroidism in individuals with occult TD.

\section{What can we learn from embryonic stem cells?}

ES cells constitute an easily manipulated model system to explore how cell fate decisions are regulated by diffusible factors. It is anticipated that findings on 


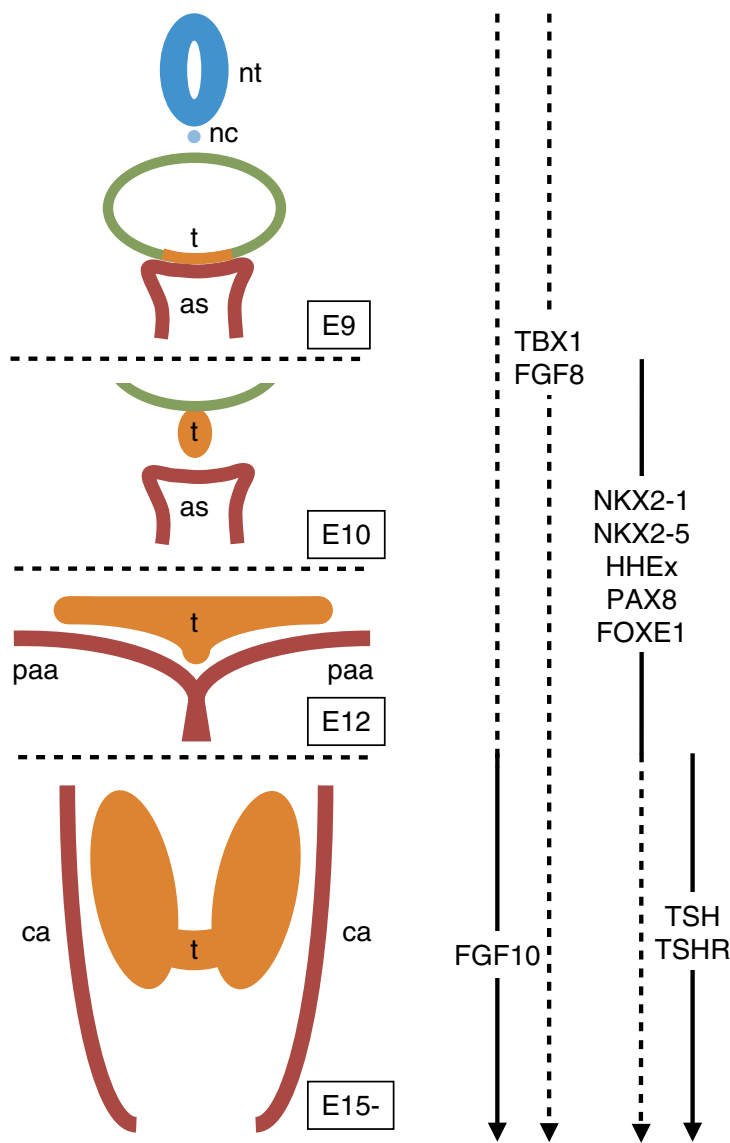

Figure $4 \mathrm{~A}$ schematic view of thyroid morphogenesis in mouse development. Cells characterized by their conjoint expression of NKX2-1, PAX8, FOXE1, and HHEX form a placode at E9 in the ventral region of the anterior gut tube (green) juxtaposed to the cardiac outflow tract (aortic sac). The bud of thyroid precursors, which assembles at $\mathrm{E} 10$, subsequently delaminates and moves downward in the neck. Between E12 and E13 the growing thyroid primordium elongates laterally along the course of pharyngeal arch arteries. After fusion with the ultimobranchial bodies (at E13.5), bilateral lobes can be clearly distinguished, and at E15.5 the final gross anatomy of the thyroid is evident. Arrows indicate the different time periods when the action of transcription factors (NKX2-1, NKX2-5, PAX8, FOXE1, HHEX, and TBX1), diffusible morphogens (FGF8 and FGF10), and TSH receptor (TSHR) signaling has been shown to be decisive to thyroid development (solid lines indicate the earliest stages where an impact on thyroid development has been demonstrated; dashed lines indicate that the onset or continued effect on morphogenesis of the factor(s) is not well defined).

ES-cell differentiation can be translated to regulatory networks governing embryonic tissue and organ development in vivo. Conversely, signaling pathways found to regulate the early steps of organogenesis have been applied in step-wise differentiation protocols of ES cells to recapitulate endogenous development in the test tube. For endoderm-derived organs this has been investigated in particular for the pancreas. By sequential addition of activin (an activator of
NODAL), WNT, FGF10, cyclopamin (an inhibitor of $\mathrm{SHH}$ ), and RA it has been possible to generate multipotent pancreatic progenitor cells expressing PDX1, and even terminally differentiated insulinproducing $\beta$-cells, from human ES cells (D'Amour et al. 2006, Kroon et al. 2008). Transplantation of $\beta$-cells generated from autologous stem cells in diabetic patients is thus a future realistic prospect.

The potential benefit of using ES cells in thyroid investigations was recently highlighted (Lin \& Davies 2010). This is still a largely unexplored field, although several interesting observations have been made. C-cells differentiated from mouse ES-cell-derived embryoid bodies (EB) express thyroid-specific genes and also form follicular structures. Furthermore, expression of PAX8 and the TSH receptor is positively regulated by TSH stimulation (Lin et al. 2003, Arufe et al. 2006, Jiang et al. 2010). In mice, TSH receptor signaling is previously known to promote thyroid differentiation but is dispensable to thyroid morphogenesis (Postiglione et al. 2002, De Felice et al. 2004). Moreover, in the mouse embryo thyroid differentiation takes place after the morphogenetic process is completed and the final thyroid anatomy is already obvious (Postiglione et al. 2002, Fagman et al. 2006). It is thus likely that TSH-stimulated thyroid differentiation as observed in EB-derived cells represents a late stage of thyroid development. A limitation of the EB model for morphogenetic studies is inherited to the inability to recapitulate the morphogenetic mechanisms that require the conjoined development of vasculature and a functional microcirculation. However, the potential of using ES cells for identifying additional factors implicated in the commitment of an undifferentiated endoderm progenitor to a thyroid cell fate is indicated by a recent study in which activin was found to promote the expression of thyroid markers in EB cells (Ma et al. 2009). Activin signaling is central in early development regulating endoderm formation by the NODAL pathway (Schier 2003). This finding is thus consistent with the endodermal origin of thyroid follicular cells.

The transcriptional regulation in cell lines is in some aspects reminiscent of embryonic regulatory programs, suggesting that studies of cells in culture may fertilize our understanding of embryonic development. An example of this is the transcriptional coactivator TAZ, recently shown to enhance in vitro the activity of PAX8 and NKX2-1 on the thyroglobulin (TG) promoter (Di Palma et al. 2009). Interestingly, TAZ is first expressed in the mouse embryonic thyroid at E14.5 coinciding with the onset of TG biosynthesis (Di Palma et al. 2009). Lack of TAZ prior to this time point may thus explain why PAX8 and NKX2-1 already expressed from E9 and onward are unable to activate the TG promoter. The reason for this is not known although it is conceivable 
that TAZ-mediated coactivation of genes at earlier stages of the development will induce premature differentiation of the embryonic thyroid. This in turn might inflict on the cells' ability to proliferate and migrate and hence disturb the morphogenetic process also regulated by PAX8 and NKX2-1. No TAZ mutations have yet been identified in patients with TD (Ferrara et al. 2009). However, TAZ is part of an intricate network that regulates multiple cell functions among which cell proliferation and migration are particularly interesting. In fact, under certain conditions TAZ is considered to be oncogenic (Chan et al. 2008). Learning more about the normal regulation of TAZ in development might thus also shed light on mechanisms governing tumor progression.

\section{What can we learn from patients?}

The genetic basis of TD leading to $\mathrm{CH}$ in humans has been a matter of discussion since many years (Abramowicz et al. 1997, Vassart \& Dumont 2005, Castanet et al. 2007, Deladoey et al. 2007b). Strikingly, most patients with TD have no mutations in genes known to affect thyroid development in animal models (see below). The precise nature and mode of action of possible genetic aberrations of TD thus remain elusive. From this it is proposed that the disease may be polygenic with a highly variable penetrance or develops sporadically on a multifactorial basis (Abramowicz et al. 1997, Castanet et al. 2010). To date, the pathogenesis of TD has been investigated experimentally mostly in monogenic mouse models in which the affected offspring follow a simple Mendelian inheritance (De Felice \& Di Lauro 2007). However, a more complex mode of transmission with a strong strain-dependent predisposition for developing TD is recognized in mice compound heterozygous for $N k \times 2-1$ and $\operatorname{Pax} 8$ (Amendola et al. 2005). The disease trait was recently linked to polymorphisms in the chromosomal region containing a chaperone partner, Dnajc17, which also was found to influence the transcriptional regulation of $\mathrm{TG}$ expression in thyroid cells (Amendola et al. 2010). A polygenic origin of TD has thus been proven in an animal model.

Although TD in humans is sporadic in the absolute majority of cases, a familial occurrence has been demonstrated in $2 \%$ of the cases, which is 15 times higher than expected by chance alone, in a large French cohort (Castanet et al. 2000, 2001, 2010). Similar findings were recently found in a less extensive Turkish study (Karakoc et al. 2008). Interestingly, both athyreosis and thyroid ectopia can be found among affected family members, implicating that heterogeneous manifestations of the disease may have a common genetic basis (Castanet et al. 2010).
A hereditary component is further suggested by observations of an increased prevalence of occult developmental anomalies of the thyroid in asymptomatic first-degree relatives (Leger et al. 2002, Adibi et al. 2008, Karakoc et al. 2008). However, it should be firmly kept in mind that monozygotic twins are generally discordant for TD (Perry et al. 2002), arguing against simple Mendelian transmission (Deladoey et al. 2007b, Castanet et al. 2010). Notably, only few germline mutations of known thyroid developmental genes (NKX2-1, PAX8, FOXE1, and HHEX) have been detected in a rather large series of patients (De Felice \& Di Lauro 2004, Al Taji et al. 2007, Ramos et al. 2009, Castanet et al. 2010, Kang et al. 2010, Montanelli \& Tonacchera 2010, Narumi et al. 2010). It is also noteworthy that linkage analysis shows no association of mutations in NKX2-1, PAX8, FOXE1, or HHEX with the TD phenotype in familial forms of $\mathrm{CH}$ (Castanet et al. 2005). From this it can be concluded that sporadic and familial cases of TD may represent distinct entities (van Vliet \& Vassart 2009). Possible mechanisms that have been put forward but not formally proven are early somatic mutations of thyroid developmental genes and epigenetic changes in gene expression (Abramowicz et al. 1997, Vassart \& Dumont 2005, Deladoey et al. 2007b). A role of environmental factors affecting thyroid development is, however, still largely hypothetical. On the contrary, the lack of a seasonal variation argues against a significant contribution of the environment (Deladoey et al. 2007a). The genetic basis of TD was recently emphasized by the finding of gene copy number variations in $9 \%$ of a patient cohort (Thorwarth et al. 2010). The genetic variations were not concentrated in recurrent hot spots favoring the idea that genetic insults eventually leading to TD are not uniform. This implies that broader chromosomal alterations may need to be elucidated to further understand the pathogenesis.

\section{Conclusions and perspectives}

The earliest stages of thyroid morphogenesis probably follow common developmental traits shared by other budding derivatives of the foregut endoderm. Although the precise inductive signal(s) that trigger multipotent endoderm progenitor cells to be committed to a thyroid fate characterized by coexpression of a thyroid-specific set of transcription factors remain to be identified, it is feasible to assume that cross talk between juxtapositioned endoderm and mesoderm is crucially involved, similar to the developmental programs operating to generate, for example, the hepatic and pancreatic lineages. However, unlike the glandular appendages of the intestine, the thyroid primordium buds off from the site of origin and moves as a free body 
to a distant location, in principle a feature shared only by the other derivatives of the pharyngeal apparatus (thymus and parathyroid). This requires additional mechanisms of which only some of the details are known today. Future work on these issues will eventually decipher the morphogenetic code of thyroid development. Rather than focusing on aberrations in putative single master genes, a broader outlook on potentially deregulated pathways is likely necessary to elucidate the complex pathogenesis of TD in man.

\section{Declaration of interest}

The authors declare that there is no conflict of interest that could be perceived as prejudicing the impartiality of the review reported.

\section{Funding}

H F was supported by an EMBO long-term fellowship, the Assar Gabrielsson Foundation, and Västra Götalandsregionen under the LUA/ALF agreement. M N was supported by project grants from the Swedish Research Council and the Swedish Cancer Foundation.

\section{Acknowledgements}

We thank Prof. Guy van Vliet for valuable comments on the manuscript.

\section{References}

Abramowicz MJ, Vassart G \& Refetoff S 1997 Probing the cause of thyroid dysgenesis. Thyroid 7 325-326. (doi:10.1089/thy.1997.7.325)

Adibi A, Haghighi M, Hosseini SR, Hashemipour M, Amini M \& Hovsepian S 2008 Thyroid abnormalities among first-degree relatives of children with congenital hypothyroidism: an ultrasound survey. Hormone Research 70 100-104. (doi:10.1159/000139152)

Al Taji E, Biebermann H, Limanova Z, Hnikova O, Zikmund J, Dame C, Gruters A, Lebl J \& Krude H 2007 Screening for mutations in transcription factors in a Czech cohort of 170 patients with congenital and early-onset hypothyroidism: identification of a novel PAX8 mutation in dominantly inherited early-onset nonautoimmune hypothyroidism. European Journal of Endocrinology 156 521-529. (doi:10.1530/EJE-06-0709)

Amendola E, De Luca P, Macchia PE, Terracciano D, Rosica A, Chiappetta G, Kimura S, Mansouri A, Affuso A, Arra C et al. 2005 A mouse model demonstrates a multigenic origin of congenital hypothyroidism. Endocrinology 146 5038-5047. (doi:10.1210/en. 2005-0882)

Amendola E, Sanges R, Galvan A, Dathan N, Manenti G, Ferrandino G, Alvino FM, Di Palma T, Scarfo M, Zannini M et al. 2010 A locus on mouse chromosome 2 is involved in susceptibility to congenital hypothyroidism and contains an essential gene expressed in thyroid. Endocrinology 151 1948-1958. (doi:10.1210/en.2009-1240)

Arnold JS, Werling U, Braunstein EM, Liao J, Nowotschin S, Edelmann W, Hebert JM \& Morrow BE 2006 Inactivation of Tbx1 in the pharyngeal endoderm results in 22q11DS malformations. Development 133 977-987. (doi:10.1242/dev.02264)

Arufe MC, Lu M, Kubo A, Keller G, Davies TF \& Lin RY 2006 Directed differentiation of mouse embryonic stem cells into thyroid follicular cells. Endocrinology 147 3007-3015. (doi:10.1210/en.2005-1239)
Bayha E, Jorgensen MC, Serup P \& Grapin-Botton A 2009 Retinoic acid signaling organizes endodermal organ specification along the entire antero-posterior axis. PLOS ONE 4 e5845. (doi:10.1371/ journal.pone.0005845)

Biben C, Weber R, Kesteven S, Stanley E, McDonald L, Elliott DA, Barnett L, Koentgen F, Robb L, Feneley M et al. 2000 Cardiac septal and valvular dysmorphogenesis in mice heterozygous for mutations in the homeobox gene Nkx2-5. Circulation Research 87 888-895.

Biben C, Wang CC \& Harvey RP 2002 NK-2 class homeobox genes and pharyngeal/oral patterning: Nkx2-3 is required for salivary gland and tooth morphogenesis. International Journal of Developmental Biology 46 415-422.

Bort R, Martinez-Barbera JP, Beddington RS \& Zaret KS 2004 Hex homeobox gene-dependent tissue positioning is required for organogenesis of the ventral pancreas. Development 131 797-806. (doi:10.1242/dev.00965)

Cai CL, Liang X, Shi Y, Chu PH, Pfaff SL, Chen J \& Evans S 2003 Isl1 identifies a cardiac progenitor population that proliferates prior to differentiation and contributes a majority of cells to the heart. Developmental Cell 5 877-889. (doi:10.1016/S1534-5807(03)00363-0)

Castanet M, Lyonnet S, Bonaiti-Pellie C, Polak M, Czernichow P \& Leger J 2000 Familial forms of thyroid dysgenesis among infants with congenital hypothyroidism. New England Journal of Medicine 343 441-442. (doi:10.1056/NEJM200008103430614)

Castanet M, Polak M, Bonaiti-Pellie C, Lyonnet S, Czernichow P \& Leger J 2001 Nineteen years of national screening for congenital hypothyroidism: familial cases with thyroid dysgenesis suggest the involvement of genetic factors. Journal of Clinical Endocrinology and Metabolism 86 2009-2014. (doi:10.1210/jc.86.5.2009)

Castanet M, Sura-Trueba S, Chauty A, Carre A, de Roux N, Heath S, Leger J, Lyonnet S, Czernichow P \& Polak M 2005 Linkage and mutational analysis of familial thyroid dysgenesis demonstrate genetic heterogeneity implicating novel genes. European Journal of Human Genetics 13 232-239. (doi:10.1038/sj.ejhg.5201321)

Castanet M, Polak M \& Leger J 2007 Familial forms of thyroid dysgenesis. Endocrine Development 10 15-28. (doi:10.1159/000106817)

Castanet M, Marinovic D, Polak M \& Leger J 2010 Epidemiology of thyroid dysgenesis: the familial component. Hormone Research in Paediatrics 73 231-237. (doi:10.1159/000284386)

Chan SW, Lim CJ, Guo K, Ng CP, Lee I, Hunziker W, Zeng Q \& Hong W 2008 A role for TAZ in migration, invasion, and tumorigenesis of breast cancer cells. Cancer Research 68 2592-2598. (doi:10.1158/0008-5472.CAN-07-2696)

Chen F, Cao Y, Qian J, Shao F, Niederreither K \& Cardoso WV 2010 A retinoic acid-dependent network in the foregut controls formation of the mouse lung primordium. Journal of Clinical Investigation 120 2040-2048. (doi:10.1172/JCI40253)

Corbetta C, Weber G, Cortinovis F, Calebiro D, Passoni A, Vigone MC, Beck-Peccoz P, Chiumello G \& Persani L 2009 A 7-year experience with low blood TSH cutoff levels for neonatal screening reveals an unsuspected frequency of congenital hypothyroidism $(\mathrm{CH})$. Clinical Endocrinology 71 739-745. (doi:10.1111/j.1365-2265.2009.03568.x)

D'Amour KA, Bang AG, Eliazer S, Kelly OG, Agulnick AD, Smart NG, Moorman MA, Kroon E, Carpenter MK \& Baetge EE 2006 Production of pancreatic hormone-expressing endocrine cells from human embryonic stem cells. Nature Biotechnology 24 1392-1401. (doi:10.1038/nbt1259)

De Felice M \& Di Lauro R 2004 Thyroid development and its disorders: genetics and molecular mechanisms. Endocrine Reviews 25 722-746. (doi:10.1210/er.2003-0028)

De Felice M \& Di Lauro R 2007 Murine models for the study of thyroid gland development. Endocrine Development 10 1-14. (doi:10.1159/ 000106814)

De Felice M, Ovitt C, Biffali E, Rodriguez-Mallon A, Arra C, Anastassiadis K, Macchia PE, Mattei MG, Mariano A, Scholer H et al. 1998 A mouse model for hereditary thyroid dysgenesis and cleft palate. Nature Genetics 19 395-398. (doi:10.1038/1289) 
De Felice M, Postiglione MP \& Di Lauro R 2004 Minireview: thyrotropin receptor signaling in development and differentiation of the thyroid gland: insights from mouse models and human diseases. Endocrinology 145 4062-4067. (doi:10.1210/en.2004-0501)

Deladoey J, Belanger N \& Van Vliet G $2007 a$ Random variability in congenital hypothyroidism from thyroid dysgenesis over 16 years in Quebec. Journal of Clinical Endocrinology and Metabolism 92 3158-3161. (doi:10.1210/jc.2007-0527)

Deladoey J, Vassart G \& Van Vliet G 2007b Possible non-Mendelian mechanisms of thyroid dysgenesis. Endocrine Development 10 29-42. (doi:10.1159/000106818)

Dentice M, Cordeddu V, Rosica A, Ferrara AM, Santarpia L, Salvatore D, Chiovato L, Perri A, Moschini L, Fazzini C et al. 2006 Missense mutation in the transcription factor NKX2-5: a novel molecular event in the pathogenesis of thyroid dysgenesis. Journal of Clinical Endocrinology and Metabolism 91 1428-1433. (doi:10.1210/jc.20051350)

Desai TJ, Malpel S, Flentke GR, Smith SM \& Cardoso WV 2004 Retinoic acid selectively regulates Fgfl0 expression and maintains cell identity in the prospective lung field of the developing foregut. Developmental Biology 273 402-415. (doi:10.1016/j.ydbio. 2004.04.039)

Dessimoz J, Opoka R, Kordich JJ, Grapin-Botton A \& Wells JM 2006 FGF signaling is necessary for establishing gut tube domains along the anterior-posterior axis in vivo. Mechanisms of Development 123 42-55. (doi:10.1016/j.mod.2005.10.001)

Di Palma T, D'Andrea B, Liguori GL, Liguoro A, de Cristofaro T, Del Prete D, Pappalardo A, Mascia A \& Zannini M 2009 TAZ is a coactivator for Pax8 and TTF-1, two transcription factors involved in thyroid differentiation. Experimental Cell Research 315 162-175. (doi:10.1016/j.yexcr.2008.10.016)

Elsalini OA, von Gartzen J, Cramer M \& Rohr KB 2003 Zebrafish hhex, nk2.1a, and pax2.1 regulate thyroid growth and differentiation downstream of Nodal-dependent transcription factors. Developmental Biology 263 67-80. (doi:10.1016/S0012-1606(03)00436-6)

Fagman H \& Nilsson M 2010 Morphogenesis of the thyroid gland. Molecular and Cellular Endocrinology 323 35-54. (doi:10.1016/j.mce. 2009.12.008)

Fagman H, Andersson L \& Nilsson M 2006 The developing mouse thyroid: embryonic vessel contacts and parenchymal growth pattern during specification, budding, migration, and lobulation. Developmental Dynamics 235 444-455. (doi:10.1002/dvdy.20653)

Fagman H, Liao J, Westerlund J, Andersson L, Morrow BE \& Nilsson M 2007 The 22q11 deletion syndrome candidate gene Tbx1

determines thyroid size and positioning. Human Molecular Genetics 16 276-285. (doi:10.1093/hmg/ddl455)

Ferrara AM, De Sanctis L, Rossi G, Capuano S, Del Prete G, Zampella E, Gianino P, Corrias A, Fenzi G, Zannini M et al. 2009 Mutations in TAZ/WWTR1, a co-activator of NKX2.1 and PAX8 are not a frequent cause of thyroid dysgenesis. Journal of Endocrinological Investigation 32 238-241.

Foley AC \& Mercola M 2005 Heart induction by Wnt antagonists depends on the homeodomain transcription factor Hex. Genes and Development 19 387-396. (doi:10.1101/gad.1279405)

Franklin V, Khoo PL, Bildsoe H, Wong N, Lewis S \& Tam PP 2008 Regionalisation of the endoderm progenitors and morphogenesis of the gut portals of the mouse embryo. Mechanisms of Development 125 587-600. (doi:10.1016/j.mod.2008.04.001)

Gilbert SF 2000 Lateral plate mesoderm and endoderm. In Developmental Biology, 6th edn, pp 471-501. Sunderland: Sinauer Associates, Inc.

Goss AM, Tian Y, Tsukiyama T, Cohen ED, Zhou D, Lu MM, Yamaguchi TP \& Morrisey EE $2009 \mathrm{Wnt} 2 / 2 \mathrm{~b}$ and $\beta$-catenin signaling are necessary and sufficient to specify lung progenitors in the foregut. Developmental Cell 17 290-298. (doi:10.1016/j.devcel.2009.06.005)

Graham A 2008 Deconstructing the pharyngeal metamere. Journal of Experimental Zoology. Part B, Molecular and Developmental Evolution 310 336-344. (doi:10.1002/jez.b.21182)
Grapin-Botton A \& Constam D 2007 Evolution of the mechanisms and molecular control of endoderm formation. Mechanisms of Development 124 253-278. (doi:10.1016/j.mod.2007.01.001)

Jiang N, Hu Y, Liu X, Wu Y, Zhang H, Chen G, Liang J, Lu X \& Liu S 2010 Differentiation of E14 mouse embryonic stem cells into thyrocytes in vitro. Thyroid 20 77-84. (doi:10.1089/thy.2008.0291)

Kaestner KH 2005 The making of the liver: developmental competence in foregut endoderm and induction of the hepatogenic program. Cell Cycle 4 1146-1148. (doi:10.4161/cc.4.9.2033)

Kameda Y, Ito M, Nishimaki T \& Gotoh N 2009 FRS2alpha is required for the separation, migration, and survival of pharyngeal-endoderm derived organs including thyroid, ultimobranchial body, parathyroid, and thymus. Developmental Dynamics 238 503-513. (doi:10.1002/dvdy.21867)

Kang IN, Musa M, Harun F \& Junit SM 2010 Characterization of mutations in the FOXE1 gene in a cohort of unrelated Malaysian patients with congenital hypothyroidism and thyroid dysgenesis. Biochemical Genetics 48 141-151. (doi:10.1007/s10528-009-9306-7)

Karakoc E, Turan S, Akpinar I, Isguven P, Adal E, Haklar G, Dede F \& Bereket A 2008 Screening of parents and siblings of patients with thyroid dysgenesis by thyroid function tests and ultrasound. Hormone Research 70 329-339. (doi:10.1159/000161863)

Kimura S, Hara Y, Pineau T, Fernandez-Salguero P, Fox CH, Ward JM \& Gonzalez FJ 1996 The T/ebp null mouse: thyroid-specific enhancerbinding protein is essential for the organogenesis of the thyroid, lung, ventral forebrain, and pituitary. Genes and Development 10 60-69. (doi:10.1101/gad.10.1.60)

Kratzsch J \& Pulzer F 2008 Thyroid gland development and defects. Best Practice and Research. Clinical Endocrinology and Metabolism 22 57-75. (doi:10.1016/j.beem.2007.08.006)

Kroon E, Martinson LA, Kadoya K, Bang AG, Kelly OG, Eliazer S, Young H, Richardson M, Smart NG, Cunningham J et al. 2008 Pancreatic endoderm derived from human embryonic stem cells generates glucose-responsive insulin-secreting cells in vivo. Nature Biotechnology 26 443-452. (doi:10.1038/nbt1393)

Krude H, Schutz B, Biebermann H, von Moers A, Schnabel D, Neitzel H, Tonnies H, Weise D, Lafferty A, Schwarz S et al. 2002 Choreoathetosis, hypothyroidism, and pulmonary alterations due to human NKX2-1 haploinsufficiency. Journal of Clinical Investigation 109 475-480. (doi:10.1172/JCI14341)

Lania G, Zhang Z, Huynh T, Caprio C, Moon AM, Vitelli F \& Baldini A 2009 Early thyroid development requires a Tbx1-Fgf8 pathway. Developmental Biology 328 109-117. (doi:10.1016/j.ydbio. 2009.01.014)

Leger J, Marinovic D, Garel C, Bonaiti-Pellie C, Polak M \& Czernichow P 2002 Thyroid developmental anomalies in first degree relatives of children with congenital hypothyroidism. Journal of Clinical Endocrinology and Metabolism 87 575-580. (doi:10.1210/jc.87.2.575)

Lien CL, Wu C, Mercer B, Webb R, Richardson JA \& Olson EN 1999 Control of early cardiac-specific transcription of Nkx2-5 by a GATAdependent enhancer. Development 126 75-84.

Lin RY \& Davies TF 2010 Differentiating thyroid cells. Thyroid 20 1-2. (doi:10.1089/thy.2009.1613)

Lin RY, Kubo A, Keller GM \& Davies TF 2003 Committing embryonic stem cells to differentiate into thyrocyte-like cells in vitro. Endocrinology 144 2644-2649. (doi:10.1210/en.2002-0122)

Lints TJ, Parsons LM, Hartley L, Lyons I \& Harvey RP 1993 Nkx-2.5: a novel murine homeobox gene expressed in early heart progenitor cells and their myogenic descendants. Development 119 419-431.

Loeber JG 2007 Neonatal screening in Europe; the situation in 2004. Journal of Inherited Metabolic Disease 30 430-438. (doi:10.1007/ s10545-007-0644-5)

Lyons I, Parsons LM, Hartley L, Li R, Andrews JE, Robb L \& Harvey RP 1995 Myogenic and morphogenetic defects in the heart tubes of murine embryos lacking the homeo box gene Nkx2-5. Genes and Development 9 1654-1666. (doi:10.1101/gad.9.13.1654) 
Ma R, Latif R \& Davies TF 2009 Thyrotropin-independent induction of thyroid endoderm from embryonic stem cells by activin A. Endocrinology 150 1970-1975. (doi:10.1210/en.2008-1374)

Martinez Barbera JP, Clements M, Thomas P, Rodriguez T, Meloy D, Kioussis D \& Beddington RS 2000 The homeobox gene Hex is required in definitive endodermal tissues for normal forebrain, liver and thyroid formation. Development 127 2433-2445.

McLin VA, Rankin SA \& Zorn AM 2007 Repression of Wnt/ $\beta$-catenin signaling in the anterior endoderm is essential for liver and pancreas development. Development 134 2207-2217. (doi:10.1242/ dev.001230)

Montanelli L \& Tonacchera M 2010 Genetics and phenomics of hypothyroidism and thyroid dys- and agenesis due to PAX8 and TTF1 mutations. Molecular and Cellular Endocrinology 322 64-71. (doi:10.1016/j.mce.2010.03.009)

Nakada C, Iida A, Tabata Y \& Watanabe S 2009 Forkhead transcription factor foxel regulates chondrogenesis in zebrafish. Journal of Experimental Zoology. Part B, Molecular and Developmental Evolution 312 827-840. (doi:10.1002/jez.b.21298)

Narumi S, Muroya K, Asakura Y, Adachi M \& Hasegawa T 2010 Transcription factor mutations and congenital hypothyroidism: systematic genetic screening of a population-based cohort of Japanese patients. Journal of Clinical Endocrinology and Metabolism 95 1981-1985. (doi:10.1210/jc.2009-2373)

Ohuchi H, Hori Y, Yamasaki M, Harada H, Sekine K, Kato S \& Itoh N 2000 FGF10 acts as a major ligand for FGF receptor 2 IIIb in mouse multi-organ development. Biochemical and Biophysical Research Communications 277 643-649. (doi:10.1006/bbrc.2000.3721)

Olivieri A, Stazi MA, Mastroiacovo P, Fazzini C, Medda E, Spagnolo A, De Angelis S, Grandolfo ME, Taruscio D, Cordeddu V et al. 2002 A population-based study on the frequency of additional congenital malformations in infants with congenital hypothyroidism: data from the Italian Registry for Congenital Hypothyroidism (19911998). Journal of Clinical Endocrinology and Metabolism 87 557-562. (doi:10.1210/jc.87.2.557)

Parlato R, Rosica A, Rodriguez-Mallon A, Affuso A, Postiglione MP, Arra C, Mansouri A, Kimura S, Di Lauro R \& De Felice M 2004 An integrated regulatory network controlling survival and migration in thyroid organogenesis. Developmental Biology 276 464-475. (doi:10. 1016/j.ydbio.2004.08.048)

Perry R, Heinrichs C, Bourdoux P, Khoury K, Szots F, Dussault JH, Vassart G \& Van Vliet G 2002 Discordance of monozygotic twins for thyroid dysgenesis: implications for screening and for molecular pathophysiology. Journal of Clinical Endocrinology and Metabolism 87 4072-4077. (doi:10.1210/jc.2001-011995)

Porazzi P, Calebiro D, Benato F, Tiso N \& Persani L 2009 Thyroid gland development and function in the zebrafish model. Molecular and Cellular Endocrinology 312 14-23. (doi:10.1016/j.mce.2009.05.011)

Postiglione MP, Parlato R, Rodriguez-Mallon A, Rosica A, Mithbaokar P, Maresca M, Marians RC, Davies TF, Zannini MS, De Felice M et al. 2002 Role of the thyroid-stimulating hormone receptor signaling in development and differentiation of the thyroid gland. PNAS $\mathbf{9 9}$ 15462-15467. (doi:10.1073/pnas.242328999)

Ramos HE, Nesi-Franca S, Boldarine VT, Pereira RM, Chiamolera MI, Camacho CP, Graf H, de Lacerda L, Carvalho GA \& Maciel RM 2009 Clinical and molecular analysis of thyroid hypoplasia: a populationbased approach in Southern Brazil. Thyroid 19 61-68. (doi:10.1089/ thy.2008.0116)

Ray MK, Chen CY, Schwartz RJ \& DeMayo FJ 1996 Transcriptional regulation of a mouse Clara cell-specific protein (mCC10) gene by the NKx transcription factor family members thyroid transciption factor 1 and cardiac muscle-specific homeobox protein (CSX). Molecular and Cellular Biology 16 2056-2064.

Schier AF 2003 Nodal signaling in vertebrate development. Annual Review of Cell and Developmental Biology 19 589-621. (doi:10.1146/ annurev.cellbio.19.041603.094522)
Schott JJ, Benson DW, Basson CT, Pease W, Silberbach GM, Moak JP, Maron BJ, Seidman CE \& Seidman JG 1998 Congenital heart disease caused by mutations in the transcription factor NKX2-5. Science 281 108-111. (doi:10.1126/science.281.5373.108)

Serls AE, Doherty S, Parvatiyar P, Wells JM \& Deutsch GH 2005 Different thresholds of fibroblast growth factors pattern the ventral foregut into liver and lung. Development 132 35-47. (doi:10.1242/ dev.01570)

Stafford D \& Prince VE 2002 Retinoic acid signaling is required for a critical early step in zebrafish pancreatic development. Current Biology 12 1215-1220. (doi:10.1016/S0960-9822(02)00929-6)

Stagi S, Lapi E, Gambineri E, Salti R, Genuardi M, Colarusso G, Conti C, Jenuso R, Chiarelli F, Azzari C et al. 2010 Thyroid function and morphology in subjects with microdeletion of chromosome 22q11 (del(22) (q11)). Clinical Endocrinology 72 839-844. (doi:10.1111/ j.1365-2265.2009.03736.x)

Stanger BZ, Tanaka AJ \& Melton DA 2007 Organ size is limited by the number of embryonic progenitor cells in the pancreas but not the liver. Nature 445 886-891. (doi:10.1038/nature05537)

Thorwarth A, Mueller I, Biebermann H, Ropers HH, Grueters A, Krude H \& Ullmann R 2010 Screening chromosomal aberrations by array comparative genomic hybridization in 80 patients with congenital hypothyroidism and thyroid dysgenesis. Journal of Clinical Endocrinology and Metabolism 95 (7) 3446-3452. (doi:10. 1210/jc.2009-2195)

Tremblay KD \& Zaret KS 2005 Distinct populations of endoderm cells converge to generate the embryonic liver bud and ventral foregut tissues. Developmental Biology 280 87-99. (doi:10.1016/j.ydbio.2005. 01.003)

Vassart G \& Dumont JE 2005 Thyroid dysgenesis: multigenic or epigenetic... or both? Endocrinology 146 5035-5037. (doi:10.1210/ en.2005-1238)

van Vliet G \& Vassart G 2009 Monozygotic twins are generally discordant for congenital hypothyroidism from thyroid dysgenesis. Hormone Research 72 320. (doi:10.1159/000245935)

Wells JM \& Melton DA 2000 Early mouse endoderm is patterned by soluble factors from adjacent germ layers. Development 127 1563-1572.

Wendl T, Lun K, Mione M, Favor J, Brand M, Wilson SW \& Rohr KB 2002 Pax2.1 is required for the development of thyroid follicles in zebrafish. Development 129 3751-3760.

Wendl T, Adzic D, Schoenebeck JJ, Scholpp S, Brand M, Yelon D \& Rohr KB 2007 Early developmental specification of the thyroid gland depends on han-expressing surrounding tissue and on FGF signals. Development 134 2871-2879. (doi:10.1242/dev.02872)

Zaret KS \& Grompe M 2008 Generation and regeneration of cells of the liver and pancreas. Science 322 1490-1494. (doi:10.1126/ science.1161431)

Zhang Z, Cerrato F, Xu H, Vitelli F, Morishima M, Vincentz J, Furuta Y, Ma L, Martin JF, Baldini A et al. 2005 Tbx1 expression in pharyngeal epithelia is necessary for pharyngeal arch artery development. Development 132 5307-5315. (doi:10.1242/dev.02086)

Zhang Z, Huynh T \& Baldini A 2006 Mesodermal expression of Tbx1 is necessary and sufficient for pharyngeal arch and cardiac outflow tract development. Development 133 3587-3595. (doi:10.1242/dev. 02539)

Zorn AM \& Wells JM 2009 Vertebrate endoderm development and organ formation. Annual Review of Cell and Developmental Biology 25 221-251. (doi:10.1146/annurev.cellbio.042308.113344)

Received in final form 12 November 2010

Accepted 8 December 2010

Made available online as an Accepted Preprint 15 December 2010 